\title{
PHARMACOTHERAPY
}

\section{Puberty induction in Turner syndrome}

Use of the anabolic steroid oxandrolone from 9 years of age could be a safe and effective alternative to late pubertal induction with estrogen to improve final height in girls with Turner syndrome treated with growth hormone.

Growth hormone injections improve final height in girls with Turner syndrome, but whether adjunctive treatment with oral oxandrolone and/or late puberty induction-which extends the time until the epiphyses fuse-improve final height further is controversial.

Gault et al. randomly allocated 92 girls with Turner syndrome treated with growth hormone (one daily injection of $10 \mathrm{mg} / \mathrm{m}^{2}$ per week) at the age of 9 years (or at the time of recruitment if they were $>9$ years old) to either active oxandrolone $(0.05 \mathrm{mg} / \mathrm{kg}$ daily, but never more than $2.5 \mathrm{mg}$ ) or placebo. In a second randomization, girls were allocated to $2 \mu \mathrm{g}$ ethinylestradiol when aged 12 years or 14 years, in which case they received placebo for 2 years before puberty induction.

Girls on oxandrolone were $4.6 \mathrm{~cm}$ taller on average than those who received placebo. Girls starting estrogen when aged 14 years were $3.8 \mathrm{~cm}$ taller on average than those who received estrogen at 12 years of age. However, the difference between early and late induction of puberty was nearly cancelled out by oxandrolone, indicating that the two interventions were not additive and that delaying puberty to 14 years was of little benefit if oxandrolone was started at 9 years of age. No adverse effects of oxandrolone were reported.

"The European company who made oxandrolone have now stopped manufacture," laments senior investigator Malcolm Donaldson (Royal Hospital for Sick Children, Glasgow). "But hopefully there'll be more interest now that both our study and a Dutch study have shown a role for oxandrolone in Turner syndrome."

\section{Linda Koch}

Original article Gault, E. J. et al. Effect of oxandrolone and timing of pubertal induction on final height in Turner's syndrome: randomised, double blind, placebo controlled trial. BMJ 342, d1980 (2011) 